\title{
Medical audit in France: historical perspective
}

\author{
Alexandra Giraud
}

Medical audit in France is dominated by a problem of semantics. The concept of medical audit is generally expressed by the words évaluation médicale, a broad definition that encompasses all the methods of quality assurance (peer review, studies of appropriateness, definition of guidelines and protocols, outcome, follow up, etc), of which medical audit is considered to be only one. The word "evaluation," however, is as vague as it is broad. The government; hospital management; the specialised institutions that have been created; and, finally, the medical profession each have their own definition depending on their respective objectives. These definitions are not necessarily congruent: they range from actual quality assurance or technology assessment for some, to cost containment for governments or hospital administrations and to clinical research for many clinicians. In this article I will use the term medical evaluation to refer to the policy in France and quality assurance to refer to the technical quality of medical care.

The development of quality assurance nationally has been observed to need two elements: political and institutional support on one hand and professional adherence and compliance on the other. In France there is no legal or customary obligation for physicians to engage in quality assurance activities, and quality assurance in the sense of quality control is not traditional among French doctors, in common with doctors in most countries. In recent years the French government has emphasised the necessity of developing medical evaluation and has lately created a national committee and a national agency to support it. The importance of medical evaluation has been emphasised in a recent hospital tour.

But the medical profession is wary of the government's intentions. As in all industrial countries, health policy in France has been dominated for the past 10 to 15 years by the constant theme of cost containment so that when doctors hear their minister tell them that they must evaluate medical care they cannot help understanding that they are being asked to save money. This does not help the profession's commitment.

\section{Medical evaluation within the profession}

Medical evaluation activities have existed within the medical profession in France for many years at two levels: hospital administrations and medical practitioners. More recently, numerous consensus conferences have also been organised by various parties.

\section{HOSPITAL ADMINISTRATIONS}

The first initiatives towards quality assurance in hospitals came from the hospital administrations of a few large hospitals in 1979-80, when the first wave of interest in medical evaluation appeared in France, from the United States. Supported by management, evaluation committees were created in many hospitals in Paris, Lyons, and Bordeaux. Several medical audits on specific subjects such as the use of antibiotics, admission waiting time, etc, were performed in hospitals. ${ }^{1}$ But in 1981 the medical profession, faced with the prospect of progressive reforms after the election of Mr Mitterrand, the first socialist president for 23 years, turned its attention to other matters. Most of the hospital evaluation committees did not even meet, and the wave of audits stopped. In 1982, the Direction for Planning of the Assistance PubliqueHôpitaux de Paris (50 hospitals) created the Committee for the Evaluation and Diffusion of Technological Innovations (Comité d'Evaluation et de Diffusion des Innovations Technologiques (CEDIT)). Composed of doctors and administrators, the committe evaluates medical, economic, and ethical aspects of new technology and subsequently plans the distribution of new technology within institutions. ${ }^{2}$ The committee is successful in its work and to this day remains the only such example of technology assessment in France.

A few years later, in 1986, at the fourth symposium of the International Society for Quality Assurance in Health Care in Paris it became apparent that France was lagging behind many other countries in quality assurance, and that French doctors were definitely interested in "evaluation"; attention returned to medical evaluation. In 1987 a quality assurance unit was created in Assistance Publique-Hôpitaux de Paris to promote quality assurance activities among their doctors. $^{3}$ Today, the development in hospitals of medical information systems derived from diagnosis related groups (the French hospital information system-Projet de Médicalisation du Système d'Information (PMSI) is directly inspired from Fetter's diagnosis related group classification system ${ }^{4}$ ) and the government's recent policy in favour of medical evaluation are expected to enhance evaluation activities in hospitals.

Initiatives from hospital administrations, however, suffer from the same ambiguity as those from the government: on one hand doctors suspect them of having financial objectives, and on the other hospital managers are usually not anxious that doctors engage in evaluation because they know that they will be asked for specific means and budgets and will be told as a result the hospital lacks equipment and staffing. Further, the French public hospitals are financed by global budgeting and if any savings are made on prescriptions, managers know that their budget can be curtailed accordingly. ${ }^{5}$

\section{CONSENSUS CONFERENCES}

France is the latest country to have taken up the method of consensus conferences for technology assessment and the definition of medical strategies. But it is catching up with lost time in the number of organised conferences. Contrary to other countries, consensus conferences in France are not managed by one single institution (OMAR in the United States, the King's Fund in the United Kingdom, $\mathrm{CBO}$ in the Netherlands), ${ }^{6}$ but the different sponsors organise their own conferences in the manner they think best. These are mostly, but not only, medical societies (for example, of intensive care, urology, and obstetrics). Assistance Publique-Hôpitaux de Paris has organised its own series of consensus conferences. This mild anarchy can lead to obvious deviations, which is why one of the first actions undertaken by the National Agency for Medical Evaluation was to publish a booklet re-emphasising the rules of consensus conference organisation. 


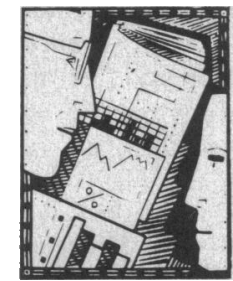

\section{MEDICAL PRACTITIONERS}

Some specialties more than others have developed medical evaluation activities: essentially general surgery, intensive care, and obstetrics, probably because results are easier to identify than in medical specialties. General surgery is the only specialty to be organised into societies for medical evaluation (Association des chirurgiens de L'Assistance publique pour l'Evaluation Médicale (ACAPEM), Association Universitaire pour la Recherche en Chirurgie (AURC), and Association pour la Recherche en Chirurgie (ARC)). Intensive care physicians have a national commission for medical evaluation and have recently issued a manual on evaluation in intensive care. ${ }^{8}$ These activities, however, consist more of evaluative and clinical research than actual quality assurance. In 1988 a society for quality assurance and technology assessment was created, which tries to disseminate the concepts of quality assurance (Société Française d'Evaluation des Soins et des Technologies (SOFESTEC)).

Within the medical profession, the problem with semantics already mentioned is coupled with one of psychology. Quality assurance in health care has come to France from the United States and most French doctors are unfamiliar with its definition and concepts. Furthermore, medical careers, in France as elsewhere, are built on research publications more than on the actual quality of care delivered (quality of care is not measured, therefore not known and not rewarded, but by virtue of the "dogma of medical infallibility" is always assumed to be the best possible). Consequently, the intellectual interests of hospital doctors incline essentially towards clinical research - that is, towards an increase in medical knowledge rather than towards control of its application. Quality assurance as such is therefore considered to be slightly trivial, and medical evaluation is in fact most often mistaken with clinical research, so that in France the concepts of quality assurance as such are not clear, and most doctors are not interested. The few medical personalities who have tried to promote actual quality assurance have met with little success.

\section{Political and institutional support of medical evaluation}

Persuaded of the importance of developing medical evaluation, the French government has recently
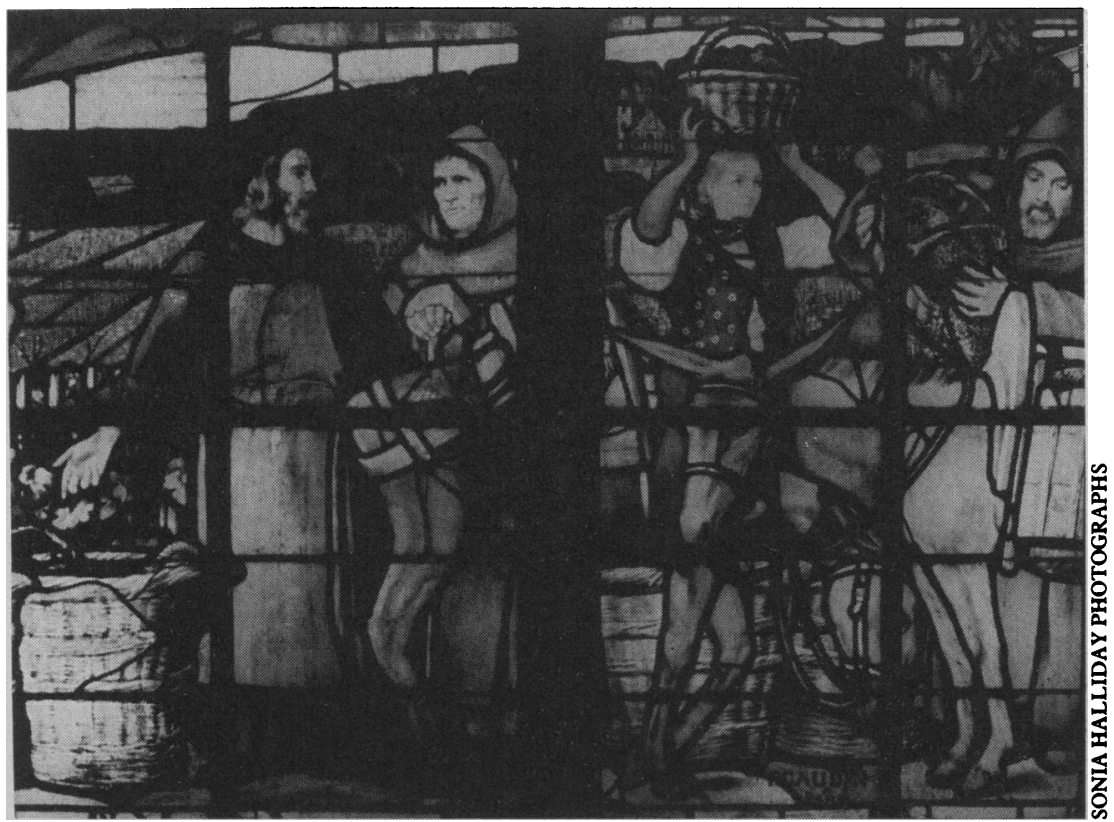

Dom Perignon window by F Gaudin, Moet et Chaudon cellars, Epernay, France created institutions to support it. Most of these were recommended in a report issued in 1989, in which the concepts of quality assurance were explained, foreign experiences described, and suggestions made for the development of quality assurance in France. ${ }^{10}$

NATIONAL COMMITTEE FOR MEDICAL EVALUATION

In its actual form, the National Committee for Medical Evaluation consists of representatives of the major medical institutions in the country: the Academy of Medicine, the National Order of Physicians, the Conference of the Deans of Medical Schools, the National Health Insurance Funds, the National Federation of Continuing Medical Education Associations, the most representative medical unions, public hospitals, etc. Its main role is to oversee evaluations being conducted and the dissemination of their results. It can suggest topics for evaluation and must continually ensure that ethical matters are respected during the phases of the evaluation process and the circulation of the results. It meets in the Ministry of Health and the heads of the main departments of the ministry are present at the meetings. It can be considered as the minister's advisory body for medical evaluation and a moral guarantee vis à vis medical ethics.

A previous national committee, instituted in 1987, had been considered ineffective in the report because it had no means for action, apart from its own moral authority.

NATIONAL AGENCY FOR THE DEVELOPMENT OF MEDICAL EVALUATION

But the most important recent measure has undoubtedly been the establishment of a National Agency for the Development of Medical Evaluation (Agence Nationale pour le Développement de l'Evaluation Médicale). Operating since 1990, the agency is headed by a professor of public health and is essentially composed of doctors. It has a scientific council headed by a renowned clinician and in which figure well known French and foreign figures in health services research and medical evaluation. The agency's assignment is to introduce quality assurance activities into the medical profession by defining and disseminating the methodologies of quality assurance procedures; assembling national and international documentation on quality assurance; and implementing quality assurance studies decided on by the scientific council, ensuring their technical follow up, and disseminating their results. The agency must also encourage the development of methodological competence in quality assurance.

In its first year, with a budget of under Fr9m (Fr8m from the ministry and $\mathrm{Fr} 0.7 \mathrm{~m}$ from the Health Insurance Fund), the agency has produced guidelines for consensus conferences along the lines of those of the National Institutes for Health in the US, performed technology assessment studies on subjects such as the prevention of post-transfusion non-A non-B hepatitis, pretherapeutic assessment of lung cancer, and preoperative assessment, etc. These studies set the standards for the subject and serve as aids to decisions for policy making as well as for the practitioner. The agency has launched a hospital quality assurance project similar to the collaborative project for developing quality assurance in European hospitals financed by the European Community's Commission for Concerted Actions (COMAC). It is also exploring ways of developing quality assurance among general practitioners with a group of 150 practitioners. This policy, however, does not include any financial incentives for doctors to engage in quality assurance.

Most importantly, the agency's mission is to disseminate information on the results of the studies 
undertaken. The results of the evaluations conducted by the agency are submitted to the national committee before their circulation.

\section{Conclusions}

Quality assurance as such is mainly a question of attitudes and behaviour. It is difficult to induce doctors to modify their behaviour by pressures other than from inside the profession. In France there are three types of understanding of medical evaluation: that of the official bodies and evaluation units of hospitals, who try to define and disseminate actual quality assurance; that of doctors, who often confuse it with clinical research; and that of government, whose main problem is financial. The fact that, except in the Netherlands, quality assurance has always been promoted by governments or health administrations, or both, and never by the medical profession itself constitutes in the eyes of doctors an original sin that is difficult to overcome. It could also turn against quality assurance itself when governments eventually find out that quantity and quality belong to two different logics and that quality assurance does not necessarily entail savings.

Therefore many problems remain before quality assurance can be integrated routinely in medical practice. Clarification is needed about the concept of quality assurance and the activities actually covered by quality assurance. Clarification is also needed about the government's intentions and its role in developing and managing quality assurance. Ideally, quality assurance should be adopted by the medical profession as an activity of its own, independent of any public or administrative policy. This is not yet the case in France, but things may be stirring.

I thank Dr L René, president of the National Order of Physicians and of the National Committee for Medical Evaluation, and Professor Y Matillon, head of the National Agency for Medical Evaluation, for their informative interviews, and Professor D Jolly and J L Portos for their constructive criticism of a first draft of this article. The opinions expressed are exclusively those of the author.

1 Jolly D, Brodin M, Stephan JC. Les Audits hospitaliers. L'hôpital à Paris 1982;68:102-4.

2 Blum-Boisgard C, Grosgogeat Y, Jolly D. Le CEDIT: 6 ans d'expérience. L'hôpital à Paris 1988;106.

3 Giraud A, Jolly D. How to induce physicians to engage in quality assurance activities in a university hospital: a policy. Quality Assurance in Health Care (in press).

4 Fetter RB, Thompson SD, Averill RF. Development, testing, and evaluation of a prospectivecase-paymentrembursement system. Final report. Yale, Connecticut: Health Systems Management Group, School of Organization and

5 Jolly D. Plaidoyer pour l'évaluation médicale. Le Monde 1991 Apr 3:18.

6 Giraud A, Jolly D. Le consensus en médecine. Méthodes et bilan des conférences de consensus dans le monde. Paris: Editions AP-Doin, 1991.

7 Agence Nationale pour le Développement de l'Evaluation Médicale. Les conférences de consensus. Bases méthodologiques pour leur réalisation en France. Paris: Agence Nationale pour le Développement de l'Evaluation Médicale, 1990

8 Le Gall JR, Loirat P, eds. Evaluation en réanimation. Paris: Masson, 1990.

9 Eddy D. The challenge. FAMA 1990;263:287-90.

10 Armogathe JF. Pour le développement de l'evaluation médicale. Paris: La Documentation Française, 1989.

\title{
Medical audit in France: from ideal to reality
}

\author{
Michel Amouretti, Claude Beraud, Elisabeth Saint-Martin
}

Gastroenterology Unit and Laboratory of Quality Assurance in Medical Care, University of Bordeaux II, 33076 Bordeaux Cedex, France

Michel Amouretti, MD, professor of

hepatogastroenterology

Elisabeth Saint-Martin,

$\mathrm{MD}$, clinical assistant

\section{Caisse Nationale \\ d'Assurance Maladie des \\ Travailleurs Salariés, \\ France \\ Claude Beraud, MD, member of council}

Correspondence to:

Dr Amouretti.

BMf 1992;304:428-30
The increasing difficulties experienced by the health service in France are causing doctors, researchers, and the politicians and administrative policy makers to put forward medical evaluation as one of the main remedies for the problems. And yet the evaluation of health care in France is rather more a hope and expectation than a reality. It is true that scientific work, particularly regarding the new technologies and public health, has been performed in France in the past 10 years; but this has been only sporadic action rather than the development of a true health care policy as conceived of in the United States and Great Britain. Moreover, there is still much conceptual confusion regarding evaluation. Bandied about daily in the press and picked up by all the health organisations and professional bodies, the term "health care evaluation" is associated by some with control strategies having an economic finality whereas for others its importance is more professional or ethical, or both. The imprecise use of the term mirrors the multiple difficulties and barriers that the concept generates within the health profession in France. Its courses are many ${ }^{1}$ : scientific, psychological, sociological, and cultural.

The time now seems right, however, for health care evaluation to develop in France, owing to the realisation of such a need by most health professionals and political and administrative health care policy makers.

Medical audit, as defined in 1989 by the NHS in Great Britain, ${ }^{2}$ covers what is beginning to be known in France as "medical evaluation of health care." The aim is to perform a systematic critical analysis of medical care, including the procedures used for diagnosis and treatment, the use of resources, and the resulting outcome and quality of life for the patient. In these terms medical audit in France has been dealt with only sporadically, through individual initiatives and the action of isolated groups, whose results are more often than not published in lesser scientific reviews and whose dissemination is limited to health professionals.

Therefore the scientific literature in the French language has produced in the past 15 years rare articles or basic reports concerning the medical evaluation of health care acts $^{3-8}$ and a few publications relating the firsthand experience of a few isolated teams. ${ }^{9-13}$ A few consensus lectures have been delivered, in no planned order, most of which have raised criticisms of methodology without being communicated to the health professionals directly concerned. ${ }^{6}$

This weakness in the production of medical audits in France goes hand in hand with the absence of any structured health policy on audit. Various official texts from the Ministry of Health concerning the establishment of regulatory practice for health care acts have either not been applied or received only transitory follow up.

And yet the need to set up such a policy is self evident: the health care system in France is one of the most costly in the 20 OECD (Organisation for Economic Cooperation and Development) countries ( $£ 4$ bn in 1990 - that is, $£ 950$ per person) while it is far from being the most efficient as shown, for example, by its ranking among OECD countries for some performance indicators (box). Health care cover by the Assurance Maladie, which has regularly dwindled in the past 10 years $(80 \%$ in $1980,74 \%$ in 1990$)$, is one of the lowest in Europe. There is also an ever increasing socioprofessional health divide. It is as if those social groups having at their disposal a large sociocultural capital are able to appropriate much more quickly than other groups the means, through technical progress, of increasing their health capital.

This gap between the high cost of the health care 